\title{
Structuring Requirements in a Multi-Project Environment in the Construction Industry A Life Cycle Perspective
}

\author{
Wörösch, Michael
}

\section{Published in:}

Proceedings of the ASME 2012 International Design Engineering Technical Conferences (IDETC) and Computers and Information in Engineering Conference (CIE)

Publication date:

2012

Link back to DTU Orbit

Citation (APA):

Wörösch, M. (2012). Structuring Requirements in a Multi-Project Environment in the Construction Industry: A Life Cycle Perspective. In Proceedings of the ASME 2012 International Design Engineering Technical Conferences (IDETC) and Computers and Information in Engineering Conference (CIE) (pp. DETC2012-70860). American Society of Mechanical Engineers.

\section{General rights}

Copyright and moral rights for the publications made accessible in the public portal are retained by the authors and/or other copyright owners and it is a condition of accessing publications that users recognise and abide by the legal requirements associated with these rights.

- Users may download and print one copy of any publication from the public portal for the purpose of private study or research.

- You may not further distribute the material or use it for any profit-making activity or commercial gain

- You may freely distribute the URL identifying the publication in the public portal 


\title{
STRUCTURING REQUIREMENTS IN A MULTI-PROJECT ENVIRONMENT IN THE CONSTRUCTION INDUSTRY - A LIFE CYCLE PERSPECTIVE
}

\author{
Michael Wörösch \\ Denmarks Technical University \\ Lyngby, Denmark
}

\section{ABSTRACT}

Being in control of requirements in building projects is vital, since it helps securing the often small profit margins and the reputation of the responsible company. Hence this research aims to introduce requirements management to the construction industry. By means of case study and action research conducted at a Danish construction syndicate producing sandwich elements made from High Performance Concrete and insulation materials it is demonstrated that requirements management successfully can be used in construction. Since requirements management as of today has not found its use in this industry, yet, success is here defined as an accomplished and accepted implementation of requirements management processes that are used by the relevant project members in their daily work and where the benefits of implementing requirements management outweighs the cost of invested resources. Furthermore it is argued that when running technology development, product development, product platform development, and a portfolio of building projects at the same time the use of requirements management is advantageous and an intelligent way of structuring requirements is needed. This article also demonstrates that the application of requirements management with gain can be extended to cover entire life cycles as e.g. the life cycle of a building. This is done by proposing a requirements structure that attempts to consider future events. The proposed structure is divided into the areas: company, technology, product platform, and building and covers all encountered types of requirements, e.g. functional (defines what a system is supposed to do), non-functional (defines how a system is supposed to be), technical, organizational, and even personal requirements. As a result the conducted research clearly shows that requirements management can be applied to the construction industry. At the same time it also becomes obvious that it is necessary to open doors to further research looking into not only using requirements databases \& processes especially designed for the construction industry but also the training of key personnel in requirements management, and how the introduction of requirements management can impact the construction industry and their customers in the long run.

\section{INTRODUCTION AND PROBLEM}

According to EU, 2010, residential and commercial buildings are responsible for about $40 \%$ of the total energy consumption and $36 \%$ of the total $\mathrm{CO}_{2}$ emission in the European Union [1]. Therefore, ambitious targets for lowering the energy consumption of new buildings and energy renovation of existing buildings are being implemented in the national and European policies, and by the year 2020 nearly zero energy buildings will become a requirement in the European Union. As a result, energy performance has become an important issue in the design of new buildings and in the renovation of existing buildings. It is expected that over the next 20 years around 40 $\%$ of all buildings need to be re-insulated. It is also expected that the requirements for saving energy that are valid in 2020 will gradually be made more rigid in the decades to follow as this has been a clear tendency up till now [2]. In this article many other examples of an ever increasing complexity that needs to be handled when running building projects will be given. In order to be able to handle this complexity and at the same time to save cost, minimize schedule delay and risk in general it is necessary to introduce requirements management to the construction industry.

In accordance with DS/EN 206-1 the lifespan of a concrete house is at least 50 years [3] and, as said by a Swedish report, the lifespan of a brick house is often more than 100 years [4]. During those years the house will be met with a lot of new requirements in respect to its size, shape, and the use of new technology. 
Therefore it makes sense to apply requirements management not only to building projects but also to the entire life cycle of buildings. Consequently, this means that a desired requirements structure has to be able to cover a lifespan of up to a hundred years and needs at the same time to be compatible to future demands, since a continuously updated requirements structure can contribute to e.g. product content documentation or calculating the life cycle cost of a construction as often requested by investors.

\section{Problem:}

The key issues and questions this article wants to give an answer to are; (1) is it practically possible and beneficial to apply requirements management to the construction industry and thereby building projects, (2) can requirements management be applied to the entire life cycle of a building and not only until the end of a building project, (3) and, if so, can the structuring of the requirements be done in a feasible way that tries to take future events into account. (1) to (3) will be illuminated in the framework of a multi-project environment as technology development, product development, product platform development and running two building projects at the same time has been a reality in the case project examined in this article.

Examples of trade-offs in the requirements structure that have been found on different levels [5, 6], will also be given.

This article is based on a case study [7] and action research [8], [9] conducted at a Danish construction syndicate. Its members established a case company called "Connovate" [10] that produces low energy buildings and insulation panels of prefabricated High Performance Concrete (HPC) sandwich elements. Figures 1 and 2 show examples of HPC sandwich elements.

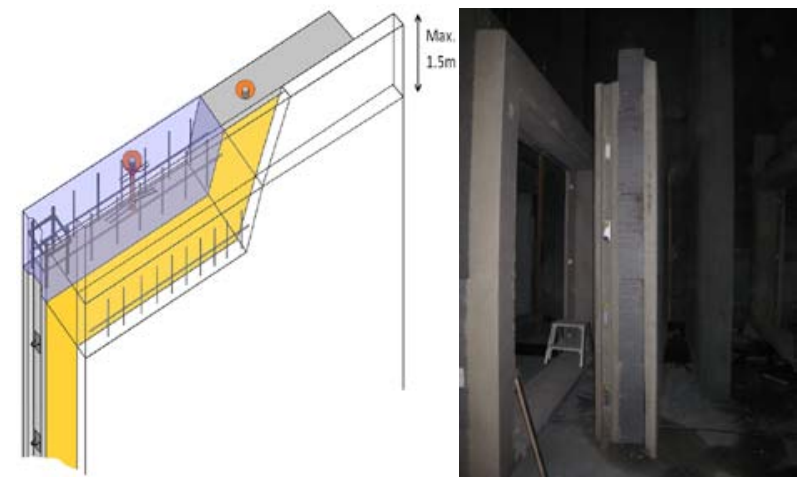

Figures 1 and 2 - A drawing and a real life picture of a HPC sandwich element

In order to live up to the European Union's requirements as well as the need for modularity, this syndicate has chosen a cradle to cradle strategy for improving many of the relevant parameters [11], as e.g. a low consumption of raw materials, a low emission of $\mathrm{CO}_{2}$ of the finished HPC sandwich elements, no use of harmful chemicals, a rational production and assembly process, a pre-fabrication design that supports modularity, and an energy optimized way of transporting the pre-fabricated HPC sandwich elements, on a running basis. This would enable the syndicate to be a building owner's sole supplier during the entire lifetime of a building. To have a clear limitation of the scope, this article assumes that requirements management is a necessary part of the daily project management $[12,13]$ and that the customers of the case company only have one supplier of building elements and man-power, who is responsible during the entire life cycle of the building.

This article is build up in the following way:

3. Literature review, 4. Research and design methods, 5. Observations, 6. Description of case, 7. Discussion of results, 8. Conclusion.

\section{LITERATURE REVIEW}

For being able to implement requirements management in the case project, mainly literature in the areas of requirements management, construction, and project management has been studied. For the described case project and therefore for this article the author believes that Fernie [14], Girmscheid [15, 16] and Krönert [13] are very relevant authors, as they are among the few who have a clear theoretical contribution to requirements management in the construction industry. Additionally Girmscheid has an impressive amount of publications covering many other useful aspects (as e.g. life cycle considerations, decision making, and a systems view when it comes to requirements) related to the construction industry as well.

For the generic project management part of this article PMI's PMBOK guide [12] and Kerzner [17] have been chosen, as they appear to cover the very most aspects of project management. This seems to be supported by the large amount of global practitioners using those two books. As for the project management part that is specific for building projects, mainly Girmscheid - but also Krönert - are able to deliver again.

The INCOSE systems engineering handbook [18] has been selected because it covers many of the areas of this article from a technical, system, and life cycle point of view.

Chapter three expressed in table form looks like this: 


\begin{tabular}{|c|c|c|c|c|c|c|c|}
\hline & Fernie[14] & \begin{tabular}{|l|} 
Grimscheid \\
{$[15],[16]$}
\end{tabular} & $\begin{array}{c}\text { Krönert } \\
{[13]}\end{array}$ & $\begin{array}{c}\text { PMBOK } \\
{[12]}\end{array}$ & $\begin{array}{c}\text { Kerzner } \\
{[17]}\end{array}$ & \begin{tabular}{|c|} 
INCOSE \\
Systems \\
eng ineering \\
handbook \\
{$[18]$} \\
\end{tabular} & This article \\
\hline $\begin{array}{l}\text { Requirements } \\
\text { management } \\
\text { in the } \\
\text { construction } \\
\text { industry - } \\
\text { theoretical } \\
\text { contribution }\end{array}$ & $x$ & $\mathrm{x}$ & $\mathrm{x}$ & Supporting & Supporting & \begin{tabular}{|l|} 
Supporting \\
\end{tabular} & $\mathrm{x}$ \\
\hline $\begin{array}{l}\text { Requirements } \\
\text { management } \\
\text { in the } \\
\text { construction } \\
\text { industry - } \\
\text { practical } \\
\text { application }\end{array}$ & Supporting & Supporting & Supporting & Supporting & Supporting & Supporting & $\mathrm{x}$ \\
\hline $\begin{array}{l}\text { Requirements } \\
\text { structure } \\
\text { covering the } \\
\text { life cycle of a } \\
\text { building }\end{array}$ & & $\begin{array}{c}\mathrm{x} \\
\text { (high level } \\
\text { proposal } \\
\text { only) }\end{array}$ & \begin{tabular}{|c|}
$x$ \\
(high level \\
proposal \\
only)
\end{tabular} & & & & $\mathrm{x}$ \\
\hline $\begin{array}{l}\text { Project } \\
\text { management }\end{array}$ & & $x$ & $x$ & $\mathrm{x}$ & $\mathrm{x}$ & $\begin{array}{l}\text { Supporting } \\
\text { (strong y) }\end{array}$ & Supporting \\
\hline $\begin{array}{l}\text { Running } \\
\text { several } \\
\text { projects in } \\
\text { parallel }\end{array}$ & & & & Supporting & Supporting & Supporting & $\mathrm{x}$ \\
\hline $\begin{array}{l}\text { Practical } \\
\text { implication of } \\
\text { several life } \\
\text { cycles of a } \\
\text { different } \\
\text { nature } \\
\text { applying at } \\
\text { the same } \\
\text { time }\end{array}$ & Supporting & \begin{tabular}{|l|l|l|l} 
Supporting \\
\end{tabular} & & Supporting & Supporting & Supporting & $\mathrm{x}$ \\
\hline $\begin{array}{l}\text { Technical } \\
\text { s/stems/ } \\
\text { Systems } \\
\text { eng ineering }\end{array}$ & $x$ & $x$ & $x$ & Supporting & Supporting & $x$ & $x$ \\
\hline
\end{tabular}

Table 1: Main literature covering the key areas of this article. " $x$ " means coverage of a certain area by a certain author

The combined literature list from above shows that several aspects still need coverage: the practical application of requirements management in building projects and a requirements structure covering the whole life cycle of a building and thereby future events. Furthermore, there seems to be no literature covering the situation of running building projects and developing product platforms, products, and new technology that is needed in those building projects in parallel. The aspect of several life cycles of a different nature applying to a project in the construction industry at the same time presumably is nowhere found in academic literature. As a consequence, the research described in this article is positioned as shown in Table 1.

\section{RESEARCH AND DESIGN METHODS}

The research described in this article is a combination of action research [8,9] and a case study [7] where there was full access to all key people and complete insight into all documents relevant to this research; including documents containing the future strategy of the case company and its products.

At the time of writing this article the research project just entered the second out of four action research cycles. The prestep explained in "Action research for operations management" [8] has not been counted as a cycle here.
An interview round with all key persons has been conducted, covering all parts of the value chain of the case project (see Figure 3) including the projects described in the chapter "Description of case". In fact, most data of this case study have been gathered during this interview round, meetings with the project stakeholders, and clarification meetings with the project teams. Please note that in the case company the customer is not the end user. Residents are end users.

The interviews have been conducted using the same questions for all participants and resulted in a master document that covered a wide range of different requirements: from functional, non-functional, technical, market, organizational requirements, to requirements towards the project manager and requirements to the stakeholders themselves.

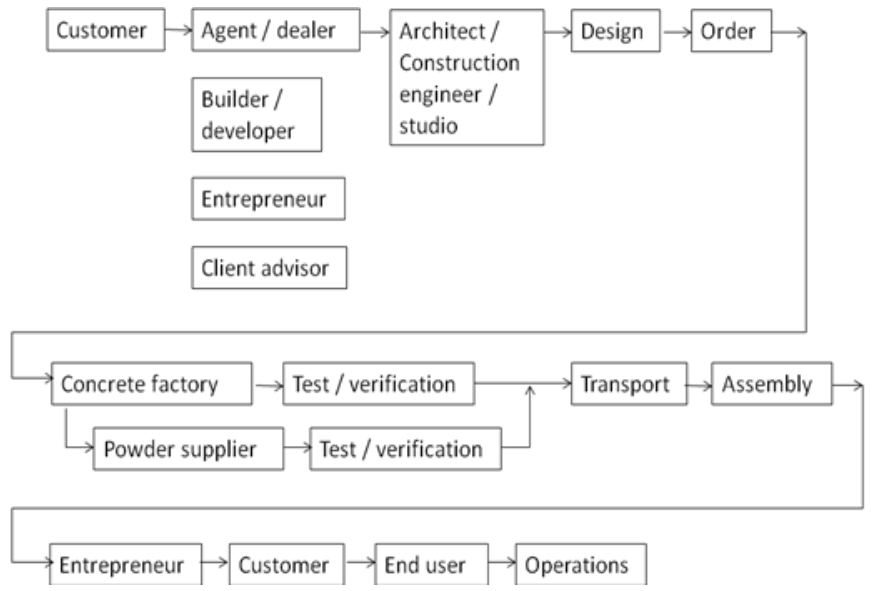

Figure 3: The value chain of the case project Footnote 1: More scenarios do exist

The authors' main task on the case project was to implement requirements management and to develop a suitable requirements structure containing all requirements of the different projects in one place, analyzing them, and linking the results to the case project's time schedule and risk register. This framing of the project work was advantageous, since the three knowledge areas - project scope management, project time management, and project risk management - are interconnected [12]. This active participation in the project has created project results that have been checked by the project staff and approved by the project manager and the project steering group. Especially the authors' proposals for how to group and prioritize the different requirements as well as the overall requirements structure, covering the different projects that are being run in parallel, has most certainly influenced the course of the case project. This can be seen by the fact that the recommended prioritization of some of the requirements over other requirements [19] and the proposed requirements structure has been widely followed by the project group. This approach is fully aligned with the principle of action research.

"The data analysis started during the interview round and continued thereafter. The research problem, questions and 
theoretical lens were applied as central pillars guiding the analysis of the case data. This involved an iterative and progressive process of questioning, reflection, theorizing and verifying each data.

The main task of the data analysis was first to gather [20]” all requirements of the different projects in the case company. Then all collected requirements were studied and structured considering the life cycles of:

a) the buildings made from the HPC of the case company,

b) the requirements themselves,

c) the building projects, and

d) the technology development project.

The reason for looking at those life cycles was that they were used for taking decisions on how to prioritize the different projects over each other and implicit in that the resources allocated to those projects. A deeper explanation of the life cycles will be given in chapter five.

The expected result of the data analysis was to get a deeper understanding of how requirements management can be applied to the construction industry and how a requirements structure that can cover the whole life cycle of a building including the technology development-, product development-, and product platform development could look like.

To accomplish this, all project goals $[15,16]$ were clearly stated and an overview table showing all expressed requirements was made. After that the project manager and the author agreed upon the relevant phases the different requirements had to be mapped into. The filled in overview table was then analyzed with respect to finding a suitable requirements structure that also considers future events.

The author is aware that Kamara et al. state "the requirements management process can be supported by using general software tools like DOORS [21] and RequisitePro [22] as no widespread requirements management tools are available in the construction industry” [23]. For reasons of transparency and flexibility in the data analysis no requirements management tools have been used in the case project.

\section{OBSERVATIONS}

While working on the case project a series of observations has been made. As discussing them is important for the success of the case project they will be covered by this article:

The phenomena that requirements management has not had its breakthrough in the construction industry, yet [15, 14], is quite interesting. In this case project, it has been examined if it is generally not possible to successfully apply requirements management to the construction industry or if this sector is simply lacking behind.

The phenomena of finding an appropriate requirements structure that tries to take future events into account and the subsequent application of requirements management to entire life cycles will also be looked into:

As fossil fuels are getting scarcer and the global warming continues to increase houses, that are being built today, will be met with a constantly increasing number of requirements on building stock from the EU. Especially requirements that are related to $\mathrm{CO}_{2}$ emission and to the materials that are used for building and remodeling will be in focus. Additionally, sensible safety requirements like, e.g. "K1, 10: a wall is only allowed to start reacting to fire after having been exposed to flames for at least 10 minutes" [24], are also constantly getting revised as new materials are put on the market.

Birgit Rasmussen [25] estimates that more than 50 out of approximately 500 million Europeans suffer from noise because their residences are not sufficiently sound insulated. It is the author's belief that the EU will also introduce new, common requirements for sound insulation in the not so far future.

On top of that are the country specific and local requirements such as the traceability of materials used in a building, as well as the self imposed requirements, e.g. when a building owner decides to remodel her building.

Since the above listed events are strongly expected or are already known to happen in the coming 50 to 100 years, it is beneficial for the case company to design a requirements structure that takes all known or assumed requirements of a buildings' life cycle into account. In fact the intention to do this has explicitly been specified in the company's philosophy.

By doing so the company can position itself as the sole supplier during the whole life cycle of a building, as already today it can make customers being aware of future requirements, the estimated price tags attached to them, and the fact that they are ready to be at the customers' side for as long as the building exists. Supported by requirements management, the corporation can in the same entire period document the content of its products. Besides, the case company will be more prepared for the future by trying to anticipate upcoming events.

The author is aware of the fact that requirements management is considered to be a supporting management process that ends at the end of the building project [13]. But, as argued above, the scope of this article is beyond a single building project, as it tries to cover the whole life cycle of a building.

The phenomena of running technology development, product platform development, product development, and a portfolio of building projects in parallel seems not to be covered by academic literature, as it is a rather special case. Nevertheless, this is reality in the case project.

Before looking at a more detailed description of the case project, the observation of several life cycles of different natures applying to the case project at the same time has to be mentioned here: 
1) The life cycle of a building in the case project:

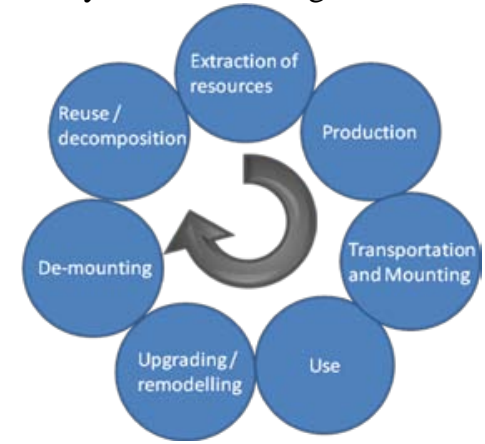

Figure 4: The life cycle of a building as met in the case project

Other product life cycle stages and a concept for life cycle design can be found in [26].

2) The life cycle of a single requirement in the case project is shown in Figure 5:

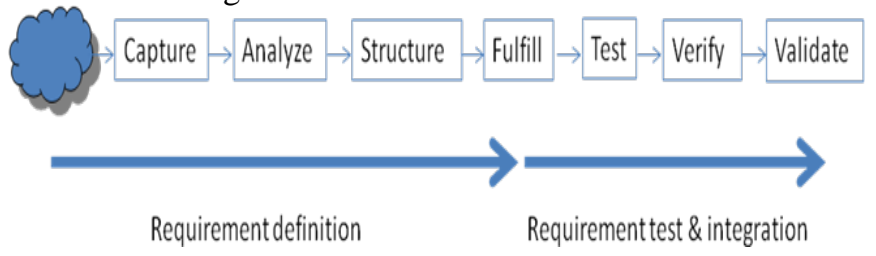

Figure 5: The generic life cycle of a requirement as encountered in the case project

The life cycle of a requirement can be divided into two main phases: The requirements definition phase and the requirements test and integration phase. The requirements definition phase consists of the following steps:

The cloud represents a high level trigger event, e.g. the start of a project. Capture means that the requirements manager is asking the different stakeholders for their requirements - the single requirement, whose life cycle we are interested in - is being stated. This requirement is then analyzed and - if not rejected during the analysis - put into a requirements structure. As the project progresses the requirement is fulfilled and ceases as such to exist.

Now the requirements test and integration phase starts: the person who has fulfilled the requirement needs to test that this really is the case. After that the person who is responsible for the work package [12], of which the fulfilled requirement is only a portion of, evaluates that this requirement and all other requirements of that work package have been incorporated in the right way (verify). The final step is to validate the requirement meaning that it has to be ensured that the requirement actually meets the user's needs and that the specifications were correct to begin with. This is typically done on a system level. During all those phases the single requirement gets more and more integrated into the total pool of requirements.
A practical example from the case project: The building project for building 75 row houses in Aarhus gets started (cloud). Specifications have been agreed upon between the case company and the customer. In order to live up to specifications the project stakeholders were asked for their requirements. One of the many requirements that had been captured was that the row houses have to be self supporting when it comes to heating. An analysis of this requirement confirmed that it is a sound requirement that the case company can live up to and wants to fulfill. Therefore this requirement has been accepted and put into the requirements structure of the building project. Once this requirement is met it stops to exist. The craftsman assembling the required heating solution to the row houses needs to check his own work and that this requirement has been fulfilled. Later in the project the owner of the work package "pipes and heating system" evaluates that the requirement has been incorporated in the right way. During the validation the requirements manager makes sure that the requirement still meets the user's needs and that the agreed specifications are correct. Once this has been done the life cycle of this single requirement has been concluded.

3) The Connovate project basically uses the life cycle phases as shown in Figure 6. A more complex example of the life cycle and phases of a building project can be found in [27].

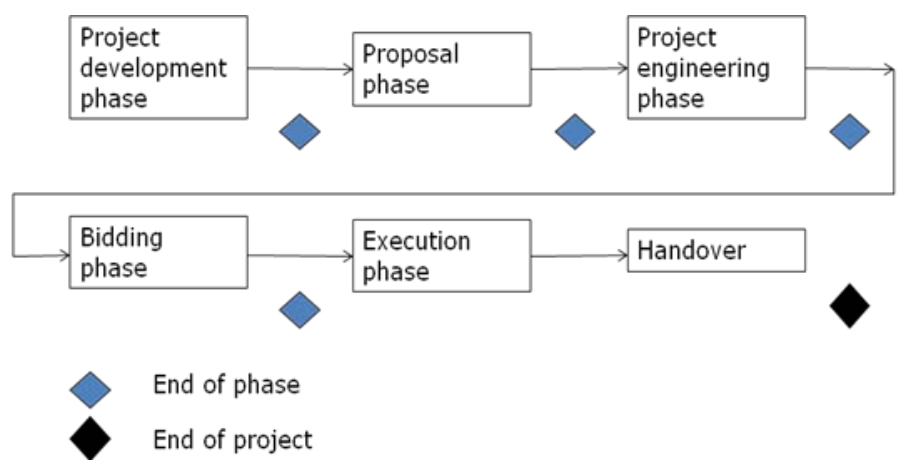

Figure 6: The phase model used in the case project

4) The new technology that is developed in this project are extremely thin but highly insulating HPC sandwich elements, additives to the powder that is used for producing the HPC, and many different ways of mounting and surface treatment of the HPC sandwich elements. Due to patent considerations the new technologies will not be described in detail. It is assumed that the life cycle of technology consists of the traditional four phases:

- Research and development phase

- Ascent phase

- Maturity phase and

- Decay phase 
Even though the nature of the above life cycles is different and the requirements linked to them vary a lot, from a time perspective it makes sense to map all four live cycles into one overview picture which helps taking decisions on what to do when and how to distribute scarce resources as it in the case project neither is possible nor seems right to work on all requirements at the same time. The vertical, gray line in Figure 7 shows a commonality three of the four life cycles have: the time stamp T1. When the building project is over, the requirements have been validated and the use of the building starts. T1 also serves as a checkpoint where the upper three life cycles and thereby their requirements should, for reasons of steering the case project, approximately be in synch. Please note that this is only a schematic comparison. The different life cycle phases can have other lengths than depicted here.

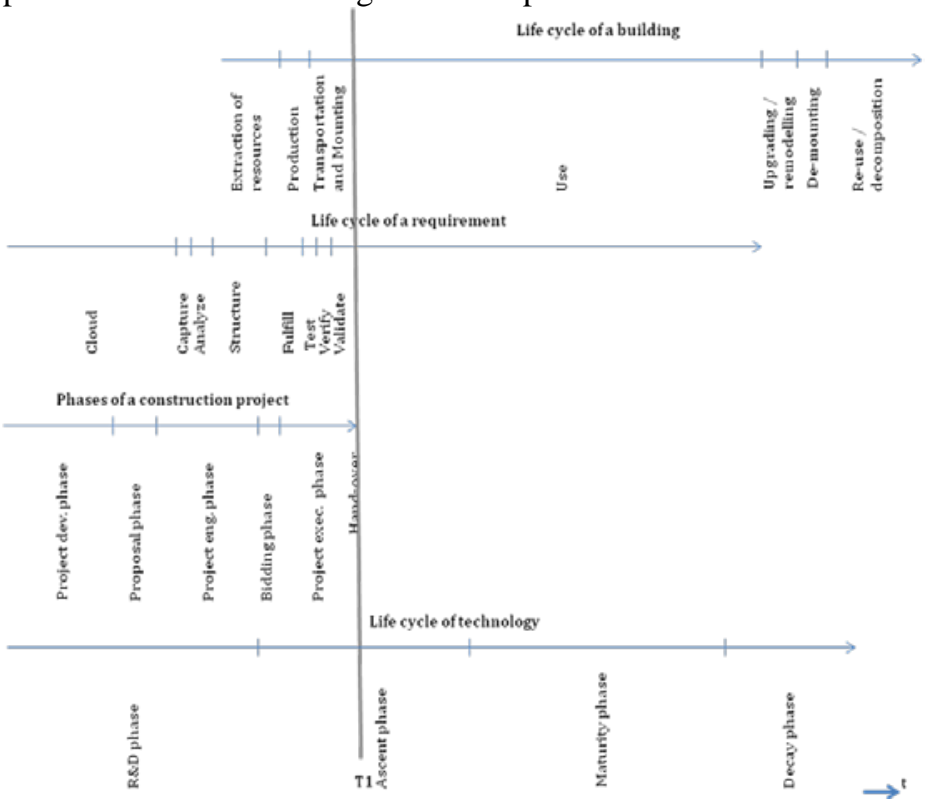

Figure 7: A schematic comparison of the different life cycles from a time point of view

One could argue that, while running a building project, in reality one typically already works in several project phases at the same time (even though there is a phase model with milestones one should comply to) and on top of that, work is done in up to four different life cycles simultaneously. Having to take decisions in such an environment where main parameters like technology, product platforms, and market can change, too, imposes many high risks on the case project. In order to reduce those risks and to keep track of so many phases all at once, the application of requirements management is once more justified.

\section{DESCRIPTION OF CASE}

\section{Background of this research}

Even though the case company is profit oriented like most other companies it has acknowledged the necessity to do research in some areas in order to move the Danish construction industry and society forward. For this reason, six $\mathrm{PhD}$ projects have been initiated where this article describes the findings of one of them.

\section{Purpose of the case project}

The described case project has the purpose to produce low energy buildings and insulation panels of pre-fabricated High Performance Concrete (HPC) sandwich elements based on new technology. At the same time the case project wants to live up to EU's 2020 energy consumption requirements.

\section{Structure and goals}

The case project consists of the following sub-projects:

- A technology development project with the goals to develop extremely thin but highly insulating HPC sandwich elements, additives to the powder that is used for producing the HPC, and many different ways of mounting and surface treatment of the HPC sandwich elements

- A product development project with the goal to develop new sandwich elements and jointing in different dimensions

- One (and soon two) platform development project(s) developing a low cost / high end platform

- Two (and soon a portfolio of) building projects:

1) In the city of Aarhus, Denmark, 75 row-houses - consisting of two floors - are currently being erected using the case companies HPC sandwich elements based on a newly developed technology. This is part of the high end building product platform.

2) In an African country a house, consisting of one floor and $40 \mathrm{~m} 2$, has been built as a show case also using the case companies HPC sandwich elements based on the same newly developed technology. This is part of the low cost building product platform.

The sub-projects have many dependencies between them. The strongest dependencies are sharing the same human and financial resources, where possible life cycle views were used to prioritize between the sub projects and to distribute resources between them. In some cases constraints, like the new technology, have to be developed first, before they can be used in the other sub projects implicitly decided where to use the resources of the case project.

As mentioned in chapter five "Observations", people typically worked in several phases of especially the building projects at the same time as well as on several life cycles simultaneously. This gave a very dynamic and innovative environment, where requirements management could be used as one of several counter measures to maintain the necessary structure that is needed in a project.

To understand the complexity of this case project it is important to know that it gets its human resources from 6 companies and 5 
research institutes. Three of those 6 companies comprise the core team and have the main responsibilities as they own the case company together. The remaining companies deliver expertise on authority requirements and knowledge of the markets in different countries. The research institutes participating have their expertise in construction (statics, insulation, and ventilation), product development and product configuration, as well as in management. All participating companies and institutes are placed in Denmark.

Using action research on such a dynamic case project seemed to be the natural choice and has so far proven to be beneficial.

\section{DISCUSSION OF RESULTS}

The research conducted in the case project gave a series of results that have been divided into the main areas this article aims at covering:

\section{Introducing requirements management to the construction industry:}

Some of the top companies working in the field of construction in Denmark have been visited and asked for their way of managing requirements and implementing them into their projects. They also got asked for the tools and processes they use when running a building project.

It was surprising to see that none of those companies had a complete overview of all the requirements that relate to the same building project gathered at one place - regardless the type of building project. Only one of those companies used a standard software tool for managing their requirements (but not the requirements of their sub contractors). Contacting one of their industry associations confirmed that picture.

Note that concerning the content of a building delivery it is customary to rely on norms and standards that cover quality, safety, indoor climate, and many other aspects [28 to 32]. Those aspects will be checked during the hand-over procedure between the entrepreneur and the customer. Instead, one could first explicitly list all known requirements in one place - even though they are often a repetition of applied norms and standards - and then define the gap. This could be done much earlier in the project which has been confirmed during company visits and the interview round.

Therefore, when starting in the case project, the application of requirements management had been discussed. Even though it was anticipated to be time consuming to implement and maintain requirements management in the case project, the benefits were expected to exceed the investment. The expected main benefit was to have a completely defined and accepted scope that accelerates the process of making a time schedule and gives plenty of input to the risk identification process. Furthermore, documenting the requirements enables sufficient testing of all relevant parts of the projects that the case project consists of. Apart from that, it seemed hard to develop new technology or pass authority approvals without an overview of all relevant requirements. For those reasons, the project manager and the project steering group of the case project agreed to implement requirements management in two steps. First, requirements management was implemented covering the technology development, the product development, and the building projects. Then, the scope was extended to also cover product platform development and the whole life cycle of the buildings that are to be delivered.

After that decision had been taken, the different key stakeholders of the case project have been visited for an interview round on their requirements. During the interview round, the interviewees were rather dedicated and contributed with a lot of information and many requirements that were not covered by norms and standards. They fully supported the decision to implement requirements management and did not find it hard to understand the processes related to it.

Already while conducting the interviews the usefulness of requirements management showed itself.

A question like: Should the building de designed to last 50 years as stated in [4] or should it be 70 or even 100 years got visible and could be thoroughly discussed as soon as the stakeholders found out that they assumed different life times.

The question of how many percent of a buildings' material should be reused showed itself when the different requirements, gathered during the interviews, were mapped into the Excel-file that covered all requirements stated for the case project. It clearly showed different expectations towards reusability. The Excel-file containing all known requirements supported the process of taking vital decisions on an informed basis as the gathered data could be grouped, filtered, and analyzed easily.

A third example of a result: while stating and comparing various requirements, the different stakeholders realized that they had had diverse expectations towards which market segments should be served presently and in the future. It needed to be clarified and communicated which market segment to serve first.

A fourth example showed that some phases of the building project had a poor coverage when it comes to requirements and test. After this had been recognized the missing requirements and tests have been identified and documented.

The last example is on the benefit for the project manager who now has one place containing all requirements of all projects he is responsible for, which makes filtering, e.g. the requirements for the different phases and the persons responsible for them, very easy. This enhances status reporting and writing project newsletters.

When all requirements had been mapped into the Excel-file the data was carefully reviewed, as the requirements had to be correct and unambiguous [33] and people got assigned to different groups of requirements. From there it only took a few weeks until a risk register and a time schedule had been available, which confirmed that the initial expectation of benefits was correct.

There were more practical examples of the results of applying requirements management to the case project. All of them pointed into the same direction: it is possible to successfully 
implement requirements management to at least parts of the construction industry.

\section{Running several projects in parallel:}

The case project consists of the following projects that are run in parallel: technology development, product platform development, product development, and two building projects. Applying requirements management, life cycle perspectives, and a division of phases to the case project, made it apparent how many projects are actually being dealt with. This was an important event in the case project, since discussions and decisions on e.g. where and how to spend resources could be based on the same picture of the world. There was also a transparency of the places where the same requirement was applicable to different projects. Especially the two in chapter six described building projects have some commonalities. Those commonalities can be used later on in the project since some test, verification, and validation results can be re-used.

The Excel-file containing the complete set of requirements for all projects, that are part of the case project, helped getting and maintaining total control of the project scope that is subject to constant revision. From an operational point of view it has so far been possible to use requirements management in a multiproject environment.

When working with requirements management in the case project one curiosity has been discovered. Typically one would expect to first have some requirements in place and then to find a practical solution to them. In all the mentioned projects once in a while it was the other way around: a possible solution was found and then the requirements were derived from that. This could be one of the main reasons for not applying systems engineering 1:1 as taught by the book.

\section{Covering the whole life cycle of a building and considering future events:}

After having conducted a series of 11 interviews, as well as stakeholder and clarification meetings, all gathered requirements had been analyzed with respect to the company strategy. The result was a list of possible future events that are likely to occur and that are probable to have an impact on: primarily the requirements on the building during its life cycle but also on the development of the company itself, the product portfolio offered by the company, and the technology developed by the company.

An adequate requirements structure for the case project should be divided into logical areas, cover parallel projects and different types of requirements, and should try to consider relevant future events as well as the life cycle of a building. In the case project the requirements structure has been divided into the areas "company level”, "technology level”, "product platform level”, and "building / physical object level”, as this division was considered the most suitable to control the single projects and at the same time to communicate with the project steering group and with other stakeholders. Other generic requirements classifications are possible. An example can be found in [34].

Identified possible future events leading to new requirements on:

company level

- The company's financial capabilities are changing which can impact the price of future deliveries and support

- New markets are being entered. E.g. investment and operational expenses requirements differ between countries

- New customer types are being served resulting in new scenarios

- Customer requirements are changing over time as a tendency

- Requirements are introduced due to branding. E.g. buildings are used as show cases

- Production requirements are changing and thereby impacting future deliveries. E.g. different format, price, quality

- New requirements associated to the cradle to cradle principle, not covered above, are being introduced

\section{technology level}

- New technology requirements are coming up. E.g. walls that are thinner than the current two centimeters limit or elements that last longer than they currently do are being requested. This is relevant for future sandwich elements

- New abilities of the material like e.g. a surface protection layer are desired

- New kinds of joints are needed

- $100 \%$ reusability of the materials that are used in the building is demanded by law

- Decomposition of materials that cannot be reused - if any is possible

\section{product platform level}

- Different new product platforms might emerge in the future. Reusing parts of the existing platforms has to be possible

- A product platform ceases to exist and will be replaced by another platform. This is only allowed to have a positive effect on existing buildings

- $\quad$ Several new kinds of buildings (product families) have to be supported by existing platforms

- Existing product platforms will change over time. A modular build-up is required. Clear interfaces need to be defined and documented

- A product configurator will be made per platform 
building level / physical object level

- New element sizes and types are needed (this can also result in new technology requirements)

- Stronger energy insulation requirements are forced upon the buildings by e.g. the EU

- Stronger sound insulation requirements are forced upon the buildings by e.g. the EU

- Stronger safety requirements are forced upon the buildings by e.g. local authorities

- Indoor climate requirements are enforced by law

- New regulatory requirements are being introduced

- New requirements are imposed by the municipalities

- Requirements for buildings being self supporting regarding heat and electricity are forced upon the buildings

- Replacement of sandwich elements is necessary and has to be possible

- Upgrading of buildings. E.g. further wiring, additional sinks is needed

- Remodeling of buildings. E.g. adding a room is needed

- Mounting and demounting of entire buildings has to be efficient

- Traceability requirements for the materials used are getting stronger

- Transportation has to consume less $\mathrm{CO}_{2}$

The above possible future scenarios are in no way exhaustive but are the current result of the project team's work.

The successful coverage of the above listed possible future events is anticipated to positively contribute to positioning the case company in the market during the entire life cycle of a building. Furthermore the company is better prepared for the future and estimates of a building's entire life cycle cost can be made as it often is requested by possible investors and by some other customers. This has been confirmed during the interviews. Looking at a whole series of possible future events and the requirements derived from that - while still implementing the requirements from the present - leads to many trade-offs. Here are some practical examples from the case project:

Trade-offs in a multi-project environment are often encountered when contradictory requirements from the different projects have to be prioritized over each other, for instance when a building project needs a new jointing system for attaching the HPC panels to the walls of a building within a few months but the technology project wants to spend more time on testing the new jointing system with the HPC elements before releasing it to the market.

Being prepared for the future costs money and is in our case often a speculative process. Despite the investment an area like the production of the sandwich elements has already been prepared for future events by buying the right, adjustable equipment and implementing flexible processes.
Having solutions in place that make future de-mounting of the building fast and easy also saves time and money in the long run, but costs money to design and implement in the present.

Another example of a trade-off is the low thickness of the concrete panels. It is today as low as two centimeters and it has taken a considerable amount of time, technology development, and approval testing to get there. Reducing this thickness even further will give additional advantages in the market but will at the same time be very resource demanding.

Analyzing trade-off scenarios often results in a go or no go decision. Generally before jumping into investments one should evaluate the probability of future events and the expected profit from the intended investment.

A very simplified extract of the requirements structure that is used in the case project today is shown in Figure 8 in Annex A. To demonstrate how future events are considered in the structure an example of changing from EU's 2020 to EU's 2025, energy consumption requirements have been added to it. The example visibly shows the interconnection of future events and thereby requirements.

Analyzing the new requirements structure filled in with all found requirements gave the following results:

- Out of over 800 new requirements more than 500 requirements have been identified that were not covered by norms and standards

- In order to cover possible future events and to have a suitable requirements structure no new headlines for requirements groups had to be added to the main level (root level; see Figure 8 in Annex A) of the Excel-file covering all requirements. It was sufficient to only add "future event requirements" to the sub-levels. Re-grouping only a few requirements was enough to get the division "company level, technology level, product platform level, and building level”.

- After the re-grouping the requirements structure has at the time of writing this article been stable for about five months

- The biggest amount of decisions that had been taken in the project was when requirements were prioritized and / or divided into work packages

- Situations where two solutions - without a previous conscious decision having been taken - were run in parallel; e.g. a product platform for high end customers and a product platform for low cost housing were targeted at the same time; it became visible that they had to be prioritized over each other. At least a decision had to be taken if work on more than one product platform could be maintained at the same time or if one product platform had to be postponed

- The added future requirements were typically interconnected, meaning adding new requirements in one area normally resulted in the need to add new requirements to several other areas (see example in Figure 8 in Annex A) 
- It got confirmed that the entire life cycle of a building and possible future events so far can be covered by the requirements structure made in the case project

- Applying the new requirements structure also had its tradeoffs:

o The time consumption, for finding possible future events which then in detail are mapped into the existing requirements structure, can be rather high. Here it is necessary to find the point where the extra hours do not yield the correlating extra benefit

o It is hard to tell what the most likely and the least likely possible future scenario is. There is a risk that the resources are spent on the wrong scenario

o Having a complex overview sheet showing all requirements and then adding future event requirements to it can make it difficult to keep the total overview and focus. Working with requirements management tools is preferable. Especially when handling requirements updates

Encouraging practical results have been delivered in all areas this article wants to cover. Requirements management has successfully been implemented in the case project and a suitable requirements structure has been found. Both have so far been tried out successfully in a multi-project environment. It is now time to use requirements management on other buildings and building projects of the case company before applying the new knowledge to other areas of the construction industry.

\section{CONCLUSION}

By applying requirements management to the described case project it has been shown that requirements management successfully can be applied to at least some parts of the construction industry. This has been done in two steps: first, requirements management was implemented covering the technology development, product development, and the two building projects. Then, the scope was extended to also cover product platform development and the whole life cycle of the buildings that are to be delivered. The reason for doing so was that - as explained in the article - a lot of new requirements will be forced upon a new building during its lifetime.

Focusing on the entire life cycle has its advantages as one is forced to think about future events and their likelihood to occur. It also supports estimating the life cycle cost of a building and the cost of possible future events, which is relevant to know for possible investors and buyers.

In order to come that far, it was essential to find a smart requirements structure that tries to consider future events and that can be used in a multi-project environment. In this article a simple and practical attempt for making such a new requirements structure has been demonstrated.

During the next two years the usefulness of the proposed new requirements structure will be observed in the case project. In that period it is also intended to apply the found requirements structure to other buildings and building projects of the case company in order to verify and improve the structure even further. The predicted future requirements will be documented and analyzed as they become a reality.

The use of requirements management in the construction industry looks very promising but is still at an early stage. Therefore more practical experience and further research is needed.

\section{Future research}

After having looked into getting an operational requirements structure it will be interesting to do future research in the following vicinities:

- The use of requirements databases and processes especially designed for the construction industry

- Training of key personnel in requirements management. A whole field needs to be educated in the practical application of requirements management. How can training of a whole field be done in an efficient way?

- How does introducing requirements management to the construction industry impact this industry and its customers in the long run?

- Is the project management model used in the case project the best choice when working with the new requirements structure and the different life cycles?

- The probability of the occurrence of the found possible future events has to be looked into so that a life cycle cost model and tool can be made that has a practical use for possible investors

- Data on the stability of the requirements have to be collected. This will also contribute to the making of an operational life cycle cost model and tool

\section{REFERENCES}

[1] http://europa.eu/legislation_summaries/energy/energy_effici ency/en0002 en.htm

[2] http://europa.eu/rapid/pressReleasesAction.do?reference $=\mathrm{M}$ EMO/08/699\&format=HTML

[3] DS/EN 206-1

[4] Kostnadsjämförelser af åtta väggtyper, 11.08.2008, Anna Barosen, White

[5] Alexander, I.F. and Stevens, R: Writing better requirements 2002

[6] Robertson, J and Robertson, S., Mastering the requirements process, 1999

[7] Robert K. Yin, Case study research, Design and methods, Fourth edition, Applied social research methods series vol. 5

[8] Paul Coughlan and David Coghlan, Action research for operations management, University of Dublin, Trinity College, Dublin, Ireland, International Journal of Operations \& Production Management, Vol. 22, No. 2, 2002, pp. 220 - 240 [9] Peter Checkland and Sue Holwell, Action Research: Its Nature and Validity, Systematic Practice and Action Research, Vol. 11, No. 1, 1998

[10] http://www.dbb.as/Connovate_Building 
[11]http://www.vuggetilvugge.dk/index.php/cradle-tocradle.html

[12] PMBOK (2008) A Guide to the Project Management Body of Knowledge (PMBOK guide), fourth edition, Project Management Institute. ISBN 9781933890517

[13] Nils Krönert, Anforderungs-Engineering im Bauwesen, Diss. ETH Nr. 19298, ISBN 978-3-906800-19-6

[14] Scott Fernie, Stuart D. Green, Stephanie J. Weller, Dilettantes, discipline and discourse: Requirements management for construction, Engineering, construction and architectural management, Volume 10 number 5, 2003, pp. 354 $-367$

[15] G. Girmscheid, Anforderungs Engineering Prozessmodel (AEP) - Modelentwicklung und Zielentwicklungsprozess -Teil 1, Bauingenieur Band 85, May 2010

[16] G. Girmscheid, Anforderungs Engineering Prozessmodel (AEP) - Anforderungsentwicklungsprozess und Zielerreichungs controlling - Teil 2, Bauingenieur Band 85, May 2010

[17] Harold Kerzner, PhD, Project Management A systems approach to planning, scheduling, and controlling, Eighth edition, 2003, ISBN 0-471-22577-0

[18] Systems engineering handbook, A guide for system life cycle processes and activities, INCOSE-TP-2003-002-03.2.1, January 2011

[19] Jim Azar, Orasi Software, Randy K. Smith and David Cordes, University of Alabama, Value-Oriented Requirements prioritization in a small development organization, IEEE SOFTWARE Published by the IEEE Computer Society 0740 7459 / 07 / \$20.00 (C) 2007 IEEE

[20] Habib Mahama, Wai Fong Chua, The effect of accounting control choices and practices in the emerge and enactment of supply alliances

[21] http://www-01.ibm.com/software/awdtools/doors/

[22] http://www-01.ibm.com/software/awdtools/reqpro/

[23] Capturing client requirements in construction projects. Kamara, J. M., Anumba, C. J., Evbuonvam, F.O. 2002

[24] De nye europæiske brandklasser, Dansk Brand- og Sikringsteknisk Institut, http://www.hfb.dk/fileadmin/templates/hfb/dokumenter/Oversi gtsstof/brandklasser.pdf

[25] Birgit Rasmussen, "Sound insulation between dwellings Requirements in building regulations in Europe" Applied Acoustics 71(2010) 373-385.

[26] MULTIOBJECTIVE OPTIMIZATION METHOD FOR LIFECYCLE DESIGN OF MACHINE PRODUCTS: Kenji Doi et al., Department of Aeronautics and Astronautics, Kyoto University, Proceedings of the ASME 2008 International Design Engineering Technical Conferences \& Computers and Information in Engineering Conference IDETC/CIE 2008, August 3-6, 2008, Brooklyn, New York, USA

[27] G. Girmscheid, D Lunze, Paradigmawechsel in der Bauwirtschaft - Lebenszyklusleistungen, Bauingenieur, Band 83, Februar 2008

[28] EN ISO 10456
[29] DS/EN ISO 12572

[30] DS/EN 12865

[31] DS/EN 12114

[32] DS/EN 13670

[33] "Requirements cannot be made explicit at all”: David C. Sutton, Linguistic problems with requirements and knowledge elicitation, Requirements engineering (2000) 5 : 114 - 124

[34] A NEW CONCEPT FOR REQUIREMENTS DRIVEN PROJECT PLANNING IN AN INTEGRATED PLM ENVIRONMENT: Michael Maletz et al., Virtual Vehicle Competence Center, Graz, Austria, Proceedings of the ASME 2008 International Design Engineering Technical Conferences \& Computers and Information in Engineering Conference IDETC/CIE 2008, August 3-6, 2008, Brooklyn, New York, USA 


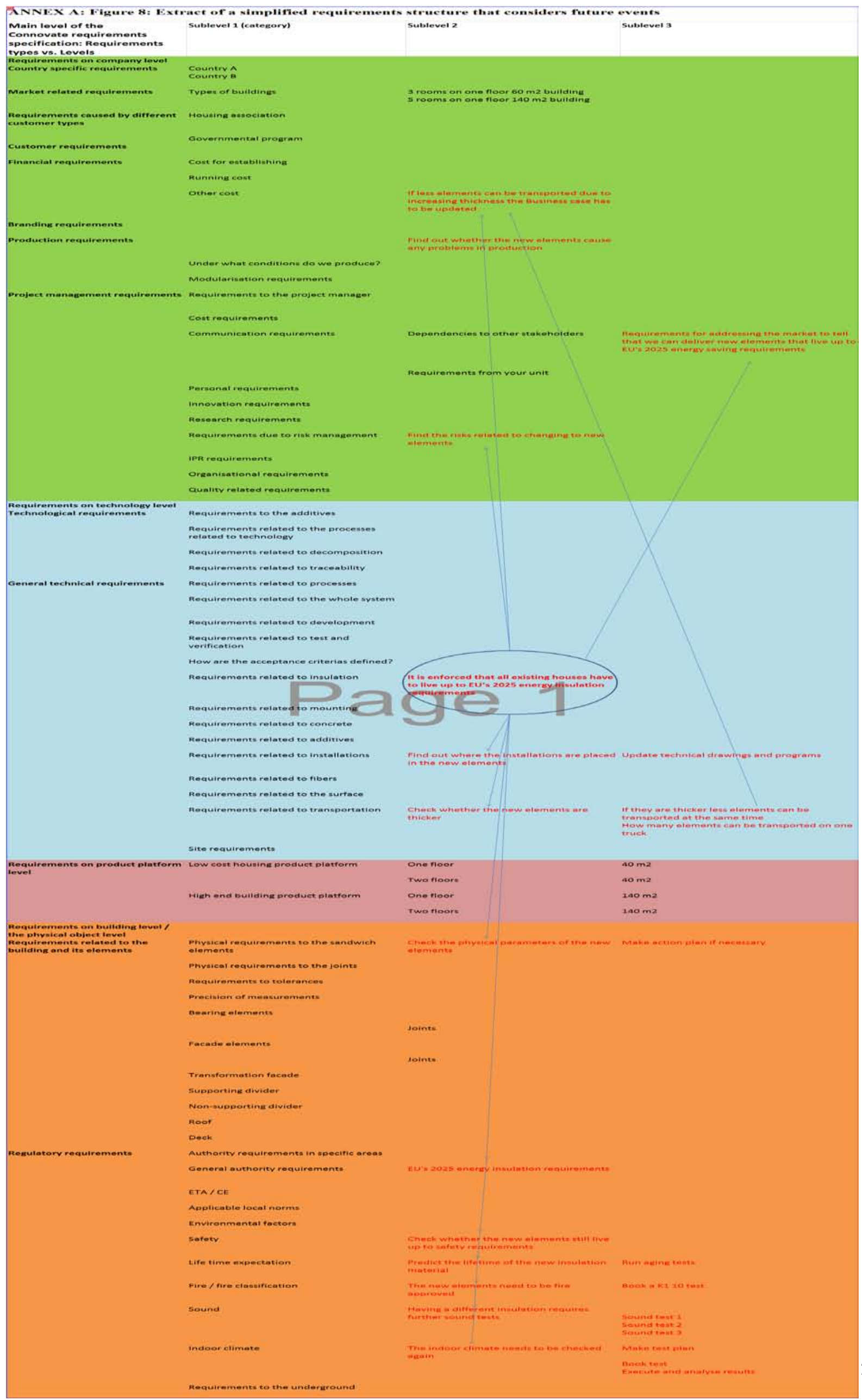

